\title{
Alcohol Use and Associated Factors among Adolescent Students in Thailand
}

\author{
S Pengpid ${ }^{1,2}, \mathrm{~K}_{\text {Peltzer }}{ }^{2,3}$
}

\begin{abstract}
Objective: Alcohol misuse is a relevant public health issue in Thailand. The assessment of the prevalence of alcohol use among adolescents may guide policies and programmes aimed at reducing alcohol use among this age group.

Method: Using data from the Thailand Global School-based Student Health Survey (GSHS) 2008, we assessed the prevalence of alcohol use and the associated factors among adolescents $(n=2758)$.

Results: Overall, the prevalence of current alcohol use was $14.8 \%(21.2 \%$ males and $9.3 \%$ females). Variables positively associated with the outcome in multivariable analysis among boys were older age, other substance use (smoking and illicit drug use), sex in the past 12 months, physical fighting, injury in the past 12 months; and among girls, poverty, smoking, physical fighting and lack of parental or guardian connectedness.

Conclusion: Efforts to prevent and control alcohol misuse may need to address a cluster of risk behaviours including cigarette smoking.
\end{abstract}

Keywords: Adolescents, alcohol use, protective factors, psychosocial distress, social correlates, Thailand

\section{El Uso de Alcohol y Factores Asociados entre los Estudiantes Adolescentes de Tailandia \\ S Pengpid ${ }^{1,2}, \mathrm{~K}$ Peltzer ${ }^{2,3}$}

\begin{abstract}
RESUMEN
Objetivo: El abuso del alcohol es un problema de salud pública importante en Tailandia. La valoración de la prevalencia del uso de alcohol entre los adolescentes puede guiar las políticas y programas encaminados a reducir el uso del alcohol entre este grupo etario.

Método: Usando datos de la Encuesta Mundial de Salud Escolar (GSHS) 2008, efectuada en Tailandia, se evaluó la prevalencia del uso del alcohol y los factores asociados, entre los adolescentes $(n=2758)$. Resultados: En general, la prevalencia del uso del alcohol corrientemente fue $14.8 \%$ (21.2\% varones y $9.3 \%$ hembras). Las variables positivamente asociadas con el resultado del análisis multivariable entre los muchachos fueron: tener más edad, uso de otra sustancia (hábito de fumar y uso ilícito de droga), sexo en los últimos 12 meses, pelea física, lesión en los últimos 12 meses. Entre las muchachas estas variables fueron: la pobreza, el hábito de fumar, la pelea física, y la falta de relación con los padres o los tutores.

Conclusión: Los esfuerzos por prevenir y controlar el abuso del alcohol entre los adolescentes pueden llevar a la necesidad de abordar una serie de comportamientos de riesgo, incluyendo el hábito de fumar.
\end{abstract}

Palabras claves: Adolescentes, uso del alcohol use, factores de protección, dificultades psicosociales, correlatos sociales, Tailandia

West Indian Med J 2012; 61 (9): 890

From: ${ }^{1}$ ASEAN Institute for Health and Development, Mahidol University, Bangkok, Thailand, ${ }^{2}$ Department of Psychology, University of Limpopo, Turfloop, South Africa and ${ }^{3}$ HIV/AIDS/SIT/and TB (HAST), Human Sciences Research Council, Pretoria, South Africa.
Correspondence: K Peltzer, HIV/AIDS/SIT/and TB Research Programme, Human Sciences Research Council, Private Bag X41, Pretoria 0001, South Africa. E-mail: kpeltzer@hsrc.ac.za 


\section{INTRODUCTION}

Alcohol use during adolescence greatly increases the likelihood that an alcohol use disorder will develop later in life (1). In a national household survey in Thailand in 2007, current alcohol use among adolescents (12-19 years) was $17.9 \%$ among males and $7.3 \%$ among females (2) and in a national high school and vocational college survey of 2007-2008 in Thailand, the prevalence rates of past-year drinking, past-30day binge drinking, and drinking until intoxication were 25.5, 9.5, and $17.3 \%$ in boys and $14.5,3.7$ and $7.2 \%$ in girls, respectively (3). Other local studies among adolescents in Thailand found similar rates of current alcohol use [among females: $9.4 \%, 9.9 \%, 12.1 \%, 13.6 \%$ and among males: $12.2 \%$, $17.7 \%, 22.7 \%, 24.2 \%$ and $25.4 \%]$ (4-8).

Factors associated with alcohol use in adolescents include other substance use $(9,10)$, other health risk behaviour [physical fighting, being bullied, sexual activity] $(3,6,9)$, injury (11), lack of school attendance $(9,12)$ psychosocial distress [anxiety, depression, suicidal behaviour] $(3,6,9,10$, 13), adverse childhood events (14), family members with alcohol problems $(4,15)$, peers drinking alcohol $(15)$, lack of protective factors such as parental supervision $(9,12,13)$, alcohol expectancies $(16,17)$, personality characteristics (16), male gender $(2,7)$, educational level $(4,5,7)$, older age (12) and grade point average (4). There is a lack of studies on protective factors and psychological distress in relation to alcohol use among adolescents in Thailand. In order to inform the design and implementation of public health intervention aimed at alcohol use, there is need for the identification of variables including psychological distress and protective factors that are associated with adolescent alcohol use. Therefore, the aim of this study was to identify factors associated with alcohol use among in-school adolescents in a national probability sample in Thailand.

\section{SUBJECTS AND METHODS}

\section{Participants and procedures}

The study involved the secondary analysis of existing data from the 2008 Thailand Global School-based Health Survey (GSHS). Details and data of the GSHS can be accessed at http://www.who.int/chp/gshs/methodology/en/index.html. The aim of the GSHS is to collect data from students aged 13 to 15 years. The Thailand GSHS was a school-based survey of students in grades 7, 8, 9 and 10. A two-stage cluster sample design was used to collect data to represent all students of grades 7, 8, 9 and 10 in the country. The first-stage sampling frame consisted of all schools containing any of grades 7-10. Schools were selected with probability proportional to school enrolment size. Thirty schools were selected to participate in Thailand GSHS.

The second stage of sampling consisted of randomly selecting intact classroom (using a random start) from each school to participate. All classrooms in each selected school were included in the sampling frame. All students in the sampled classroom were eligible to participate in the GSHS (18). From the 2008 statistical information of the Ministry of Education, there were 2622210 students in grades 7-10; 2963 students or $0.11 \%$, both males and females, were selected as a sample in this research (18). The school response rate was $100 \%$, the student response rate was $93 \%$, and the overall response rate was $93 \%$. Students self-completed the questionnaires to record their responses to each question on a computer scanable answer sheet. A total of 2767 students participated in the Thailand GSHS (18). The GSHS 11 core questionnaire modules address the leading causes of morbidity and mortality among children and adults worldwide: tobacco, alcohol and other drug use, dietary behaviours, hygiene, mental health, physical activity, sexual behaviours that contribute to HIV infection, other sexually transmitted infections and unintended pregnancy, unintentional injuries and violence, protective factors and respondent demogra-phics $(18,19)$

\section{Measures}

Alcohol use: The main alcohol use question was, "During the past 30 days, on how many days did you have at least one drink containing alcohol?" Current drinking was defined as drinking alcohol on any of the days in the past 30 days.

Other substance use variables: Tobacco smoking in the past 30 days was assessed with the question, "During the past 30 days, on how many days did you smoke cigarettes?" Response options included $1=0$ days to $7=$ all 30 days. Drug use: "During your life, how many times have you used drugs, such as methamphetamines (Yaba), ecstasy, $4 \times 100$, or marijuana?"

Poverty: A measure of poverty was derived from a question reporting the frequency that a young person went hungry because there was not enough food at home in the past 30 days. There were five response options ranging from never to always, which were dichotomized to never/rarely and sometimes/most of the time/always.

Exposure to bullying: To assess exposure to bullying behaviour, students were prompted with the following: "Bullying occurs when a student or group of students say or do bad and unpleasant things to another student. It is also bullying when a student is teased a lot in an unpleasant way or when a student is forced to withdraw from certain activities on purpose. It is not bullying when two students of about the same strength or power argue or fight or when teasing is done in a friendly and hilarious way." Students were then asked the following question: "During the past 30 days, on how many days were you bullied?" Those reporting one or more days were considered to have been bullied.

Physical fights: To assess physical fights, students were prompted with the following: "Physical fights occur when two or more students of about the same strength or power choose to fight each other." Students were then asked, "During the past 12 months, how many times were you in a 
physical fight?" Those reporting once or more times in a physical fight in the past 12 months were considered to be physically fighting.

The sexual behaviour item included in this analysis was: "During the past 12 months, have you had sexual intercourse?" Response option was "yes" or "no".

Physical activity was assessed with two questions about the number of days with physical activity of at least 60 minutes during the past seven days and during a typical week. Introductory statements to the questions included country specific examples of the activities and specified that physical education or gym class should not be included (19). Physically inactive was defined as not obtaining at least 60 minutes of physical activity per day on at least five days per week (20). For analysis, the number of active days "during the past week" and "during a typical week" were averaged. Psychosocial distress variables: Loneliness: "During the past 12 months, how often have you felt lonely?" (Response options were from $1=$ never to 5 = always, which were dichotomized into most of the time or always and never, rarely or sometimes). Anxiety or worried: "During the past 12 months, how often have you been so worried about something that you could not sleep at night?" (Response options were from 1 = never to 5 = always). Sadness: "During the past 12 months, did you ever feel so sad or hopeless almost every day for 2 weeks or more in a row that you stopped doing your usual activities?" (Response option $1=$ yes and $2=$ no). Suicide plan: "During the past 12 months, did you make a plan about how you would attempt suicide?" (Response option was $1=$ yes and $2=$ no, coded 1 $=1,2=0)$.

Protective factors (school attendance, peer support at school, parental or guardian supervision, connectedness, and bonding). School attendance: "During the past 30 days, on how many days did you miss classes or school without permission?" (Response options were from $1=0$ times to $5=10$ or more times (coded $1=0$ times and $0=1$ or 2 to 10 or more times). Peer support at school was assessed with the question "During the past 30 days, how often were most of the students in your school kind and helpful?" Parental or guardian supervision: "During the past 30 days, how often did your parents or guardians check to see if your homework was done?" Parental or guardian connectedness: "During the past 30 days, how often did your parents or guardians understand your problems or worries?" and Parental or guardian bonding: "During the past 30 days, how often did your parents or guardians really know what you were doing with your free time?" Response options to these questions were from $1=$ never to $5=$ always, which was dichotomized into never or rarely and sometimes to always.

\section{Data analysis}

Data analysis was performed using STATA software version 10.0 (Stata Corporation, College Station, TX, USA). This software has the advantage of directly including robust standard errors that account for the sampling design ie cluster sampling owing to the sampling of school classes. A weighting factor was applied to each student record to adjust for non-response and for the varying probabilities of selection. The weighting formula used for this GSHS dataset was: $\mathrm{W}=\mathrm{W} 1 * \mathrm{~W} 2 * \mathrm{f} 1 * \mathrm{f} 2 * \mathrm{f} 3$ [Base weight: $\mathrm{W} 1=$ the inverse of the probability of selecting each school and $\mathrm{W} 2=$ the inverse of the probability of selecting each class room; nonresponse adjustment: $\mathrm{fl}=\mathrm{a}$ school-level non-response adjustment factor and $\mathrm{f} 2 \mathrm{a}$ a student-level non response adjustment factor calculated by classroom; post stratification adjustment: $\mathrm{f} 3=$ a post stratification adjustment factor calculated by sex within grade] (18).

Psychosocial distress was assessed across the four mental health measures when a student's response was indicative of distress: loneliness, anxiety or worried, sadness and suicide plan. The number of psychosocial distress indicators was calculated by determining if students had $0,1,2$ and 3 or 4 indicators. Associations between current alcohol use and sociodemographics, other substance use, other health risk behaviour, psychosocial distress variables and protective factors were evaluated calculating odds ratios (OR). Unconditional logistic regression was used for evaluation of the impact of explanatory variables on current alcohol use (any alcohol drink in the past 30 days) [binary dependent variable]. All variables statistically significant at the $p<0.05$ level in bivariate analyses were included in the multivariable models. In the analysis, weighted percentages are reported. The reported sample size refers to the sample that was asked the target question. The two-sided $95 \%$ confidence intervals are reported. The $p$-values less or equal to $5 \%$ is used to indicate statistical significance. Both the reported $95 \%$ confidence intervals and the $p$-value are adjusted for the multi-stage stratified cluster sample design of the study.

\section{RESULTS}

Table 1 gives the sample characteristics of 2767 participants, mainly between 12 and 15 years old, $53.2 \%$ females and $46.8 \%$ males. Overall, the prevalence of current alcohol use was $14.8 \%$ (21.2\% males and $9.3 \%$ females). Among current drinkers, the majority $(62.4 \%)$ was drinking alcohol one or two days and $36.6 \%$ drank more than three days in the past 30 days; $16.6 \%$ drank five or more drinks per day on a usual day. Almost one in five (19\%) had ever drunk to the extent of getting drunk completely, and among those who ever got drunk in their life, $11.4 \%$ got drunk 10 or more times during their lifetime. Current smoking and current other tobacco use were reported by $8.2 \%$ and $7.2 \%$, respectively. Overall, lifetime illicit drug use was $6.0 \%$. Sexual intercourse in the past 12 months was reported by $11 \%$ of the adolescents. Substance use and sexual behaviour variables were all higher among males than females. More than a quarter (26.6\%) of the participants had at least one psychosocial distress indicator. 
Table 1: Characteristics of adolescents in Thailand*

\begin{tabular}{|c|c|c|c|}
\hline & $\begin{array}{c}\text { Total } \\
(\mathrm{n}=\mathbf{2 7 6 7 )} \\
\mathrm{n}(\%)^{2}\end{array}$ & $\begin{array}{c}\text { Males } \\
(\mathrm{n}=\mathbf{1 3 6 5}) \\
\mathrm{n}(\%)^{2}\end{array}$ & $\begin{array}{c}\text { Females } \\
(\mathrm{n}=1396) \\
n(\%)^{2}\end{array}$ \\
\hline \multicolumn{4}{|l|}{ Age (years) } \\
\hline$\leq 12$ & $466(17.0)$ & $201(15.6)$ & $265(18.2)$ \\
\hline 13 & $840(29.5)$ & 407 (30.9) & $433(28.1)$ \\
\hline 14 & $870(28.7)$ & $443(30.3)$ & $427(27.2)$ \\
\hline$\geq 15$ & $582(24.9)$ & $313(23.2)$ & $269(26.5)$ \\
\hline Poverty & $94(3.4)$ & $63(4.7)$ & $31(2.1)$ \\
\hline \multicolumn{4}{|l|}{ Alcohol use } \\
\hline Current alcohol use ( 1 or more drinks in past 30 days) & $368(14.8)$ & $247(21.2)$ & $121(9.3)$ \\
\hline Drinks 1 or 2 days in past 30 days & $233(62.4)$ & $143(56.6)$ & $90(73.6)$ \\
\hline Drinks $3-30$ days in past 30 days & $135(36.6)$ & $104(43.4)$ & $31(26.4)$ \\
\hline Drinks $<1$ drink per day & $167(39.8)$ & $114(40.2)$ & $53(39.0)$ \\
\hline Drinks 1 drink per day & $87(21.1)$ & $60(22.5)$ & $27(18.6)$ \\
\hline Drinks $2-4$ drinks per day & $90(22.4)$ & $55(20.8)$ & $35(25.5)$ \\
\hline Drinks 5 or more drinks per day & $64(16.6)$ & $44(16.4)$ & $20(17.0)$ \\
\hline Lifetime drunk & $498(19.0)$ & $326(24.7)$ & $172(13.6)$ \\
\hline 1 or 2 times drunk & $348(70.5)$ & $203(62.8)$ & $145(83.5)$ \\
\hline 3-9 times drunk & $93(18.1)$ & $74(22.3)$ & $19(11.2)$ \\
\hline 10 or more times drunk & $57(11.4)$ & 49 (14.9) & $8(5.3)$ \\
\hline \multicolumn{4}{|l|}{ Other substance use } \\
\hline Current smoking & $220(8.2)$ & $190(15.0)$ & $30(2.2)$ \\
\hline Lifetime illicit drug use & $167(6.0)$ & $147(11.1)$ & $20(1.3)$ \\
\hline \multicolumn{4}{|l|}{ Other health risk behaviour } \\
\hline Sexual intercourse in the past 12 months & $291(11.0)$ & $189(14.6)$ & $102(7.6)$ \\
\hline Two or more lifetime sexual partners & $141(5.5)$ & $121(9.8)$ & $20(1.6)$ \\
\hline Fighting & $931(33.3)$ & $617(45.6)$ & $314(21.7)$ \\
\hline Being bullied & $679(27.8)$ & $383(32.9)$ & $296(23.2)$ \\
\hline Physically inactive ${ }^{1}$ & $2073(76.3)$ & $914(67.5)$ & $1159(84.6)$ \\
\hline Sitting 3 hours or more per day & $1039(37.5)$ & $518(37.7)$ & $521(37.4)$ \\
\hline \multicolumn{4}{|l|}{ Number of psychosocial distress indicators } \\
\hline 0 & $1939(73.4)$ & $935(73.3)$ & $1004(73.4)$ \\
\hline 1 & $445(16.9)$ & $206(16.6)$ & $239(17.3)$ \\
\hline 2 & $192(7.1)$ & $101(8.0)$ & $91(6.4)$ \\
\hline 3 or 4 & $65(2.5)$ & $27(2.0)$ & $38(3.0)$ \\
\hline \multicolumn{4}{|l|}{ Protective factors } \\
\hline Truancy & $467(17.1)$ & $317(24.0)$ & $150(10.6)$ \\
\hline Peer support & $1123(41.7)$ & $462(34.4)$ & $661(48.5)$ \\
\hline Parental or guardian supervision & $994(35.9)$ & $469(35.2)$ & $525(36.6)$ \\
\hline Parental or guardian connectedness & $927(34.2)$ & $384(28.7)$ & $543(39.3)$ \\
\hline Parental or guardian bonding & $1214(45.4)$ & $514(38.6)$ & $700(51.8)$ \\
\hline
\end{tabular}

*Based on data from the Thailand Global School-based Student Health Survey (GSHS) 2008. ${ }^{1}$ Physical activity less than 60 minutes per day on at least five days per week; ${ }^{2}$ Numbers may not add up to total sample due to missing values and weighted percentages are reported.

\section{Association between current alcohol use and factors} assessed

In bivariate analysis among boys, older age, poverty, other substance use, sexual activity (in the past 12 months), fighting, being bullied, injury, sedentary behaviour, psychosocial distress, lack of school attendance and lack of parental or guardian supervision and bonding were associated with current alcohol use. While in unconditional multivariable logistic regression, older age (adjusted odds ratio [AOR]: 4.35; 95\% CI 1.94, 9.76), smoking (AOR: 15.33 ; 95\% CI 6.45, 36.62), illicit drug use (AOR: 9.40; 95\% CI 3.39, 25.55), sex in the past 12 months (AOR: 1.76; 95\% CI 1.03, 3.08), physically fighting (AOR: $1.80 ; 95 \%$ CI $1.11,2.92$ ) and having been injuried in the past 12 months (AOR: 2.07; 95\% CI $1.15,3.71$ ) were associated with current alcohol use. Further, in bivariate analysis among girls, older age, poverty, other substance use, sexual activity (in the past 12 months), fighting, injury, sedentary behaviour, psychosocial distress, lack of school attendance and lack of parental or guardian supervision, connectedness and bonding were associated with current alcohol use. While in unconditional multivariable logistic regression, poverty (AOR: 3.55 ; 95\% CI 1.28, 9.79), smoking (AOR: 52.4; 95\% CI 10.3, 292.5), fighting (AOR: $2.98 ; 95 \%$ CI 1.66, 5.35) and lack of parental or guardian connectedness (AOR: 0.38 ; 95\% CI 0.18, 0.84) were associated with current alcohol use (Table 2). 


\section{DISCUSSION}

The study found an overall prevalence of current alcohol use of $14.8 \%$ (21.2\% males and 9.3\% females) among schoolgoing adolescents in Thailand. Similar rates were found adolescents is associated not only with somatic complications, but also with traffic accidents and other types of accidents, violent behaviour and suicide and a greater risk of developing an alcohol-related disorder (23).

Table 2: Bivariate and multivariable logistic regression analysis of factors that are associated with current alcohol use among adolescents in Thailand 2008

\begin{tabular}{|c|c|c|c|c|}
\hline & \multicolumn{2}{|c|}{ Male } & \multicolumn{2}{|l|}{ Female } \\
\hline & $\mathrm{OR}^{1}(95 \% \mathrm{CI})$ & $\operatorname{AOR}^{2}(95 \% \mathrm{CI})$ & OR $(95 \% \mathrm{CI})$ & $\mathrm{AOR}^{2}(95 \% \mathrm{CI})$ \\
\hline \multicolumn{5}{|l|}{$\overline{\text { Age }}$} \\
\hline$\leq 12$ years & 1.00 & 1.00 & 1.00 & 1.00 \\
\hline 13 & $1.20(0.63-2.28)$ & $1.29(0.47-3.52)$ & $0.94(0.50-1.79)$ & $0.84(0.41-1.73)$ \\
\hline 14 & $2.90(1.74-4.81)^{* * *}$ & $3.73(1.17-11.94)^{*}$ & $2.35(1.36-4.06)^{* *}$ & $1.46(0.77-2.77)$ \\
\hline$\geq 15$ years & $4.24(2.21-8.13)^{* * *}$ & $4.35(1.94-9.76)^{* * *}$ & $2.52(1.32-4.80)^{* *}$ & $1.44(0.76-2.75)$ \\
\hline Poverty & $2.00(1.01-3.97)^{*}$ & $1.30(0.14-12.10)$ & $3.65(1.28-10.38)^{*}$ & $3.55(1.28-9.79) *$ \\
\hline \multicolumn{5}{|l|}{ Other substance use } \\
\hline Current smoking & $24.0(13.6-42.2)^{* * *}$ & $15.33(6.45-36.62)^{* * *}$ & $48.3(1.4-187.5)^{* * *}$ & $52.4(10.3-292.5)^{* * *}$ \\
\hline Ever illicit drug use & $26.7(16.2-44.2)^{* * *}$ & $9.40(3.39-25.55) * * *$ & $18.4(6.1-55.3)^{* * *}$ & $4.42(0.10-196.2)$ \\
\hline \multicolumn{5}{|l|}{ Other health risk behaviour } \\
\hline Sex in past 12 months & $4.20(2.64-6.52)^{* * *}$ & $1.76(1.01-3.08)^{*}$ & $5.37(2.51-11.51)^{* * *}$ & $1.58(0.43-5.82)$ \\
\hline Fighting & $2.60(1.86-3.63)^{* * *}$ & $1.80(1.11-2.92)^{*}$ & $3.27(2.05-5.22)^{* * *}$ & $2.98(1.66-5.35)^{* * *}$ \\
\hline Being bullied & $1.76(1.43-2.15)^{* * *}$ & $0.79(0.41-1.50)$ & $1.57(0.88-2.81)$ & - \\
\hline Injury in past 12 months & $2.92(2.04-4.18)^{* * *}$ & $2.07(1.15-3.71)^{*}$ & $3.26(2.32-4.59) * * *$ & $1.45(0.75-2.81)$ \\
\hline Physically inactive & $0.92(0.65-1.29)$ & - & $1.17(0.59-2.33)$ & - \\
\hline Sitting 3 hours or more per day & $1.61(1.19-2.17)^{* *}$ & $1.30(0.66-2.56)$ & $2.09(1.48-2.94)^{* * *}$ & $1.55(0.98-2.47)$ \\
\hline \multicolumn{5}{|l|}{ Psychosocial distress } \\
\hline None & 1.00 & 1.00 & 1.00 & 1.00 \\
\hline One & $1.23(0.84-1.82)$ & $1.03(0.57-1.92)$ & $2.64(1.58-4.39)^{* * *}$ & $1.55(0.69-3.49)$ \\
\hline Two & $1.90(1.19-3.03) *$ & $1.60(0.89-2.90)$ & $3.55(1.54-8.19)^{* *}$ & $2.51(0.75-8.45)$ \\
\hline Three or more & $5.69(2.14-15.1)^{* *}$ & $2.65(0.55-12.88)$ & $3.78(1.41-10.17) *$ & $2.46(0.66-9.13)$ \\
\hline \multicolumn{5}{|l|}{ Protective factors } \\
\hline School attendance & $0.19(0.14-0.27)^{* * *}$ & $0.59(0.33-1.07)$ & $0.33(0.17-0.65)^{* *}$ & $0.69(0.32-1.48)$ \\
\hline Peer support & $0.72(0.48-1.06)$ & - & $0.63(0.37-1.06)$ & - \\
\hline $\begin{array}{l}\text { Parental or guardian } \\
\text { supervision }\end{array}$ & $0.50(0.33-0.76)^{* *}$ & $0.84(0.31-2.25)$ & $0.57(0.34-0.95)^{*}$ & $0.87(0.44-1.73)$ \\
\hline Parental or guardian connectedness & $0.82(0.57-1.20)$ & - & $0.31(0.17-0.57)^{* * *}$ & $0.38(0.18-0.84)^{*}$ \\
\hline Parental or guardian bonding & $0.51(0.35-0.74)^{* *}$ & $0.71(0.35-1.45)$ & $0.50(0.36-0.71)^{* * *}$ & $0.92(0.51-1.94)$ \\
\hline
\end{tabular}

among adolescents in previous studies in Thailand $(2-6,8)$ and in some other studies eg in Zimbabwe (9) and higher rates in some other countries eg Brazil (21) and Seychelles (12). Among those who drank in this study, 17\% engaged usually in binge drinking ( 5 or more drinks per day), this was similar among boys and girls. Similar high rates of binge drinking among adolescents were observed in other studies among adolescents in Thailand (3-6). Similar to binge drinking, from all those studied, 19\% reported to have been drunk in their lifetime; these rates are similar in a study among adolescents in four African countries (14) and lower than among those in Brazil (21). Binge drinking, also known as "drinking to get drunk" is defined "as a pattern of alcohol consumption that brings the blood alcohol concentration (BAC) levels to $0.08 \%$ or more. This pattern of drinking usually corresponds to five or more drinks on a single occasion for men or four or more drinks on a single occasion for women, generally within about two hours" (22). Episodic excessive alcohol consumption ("binge drinking") among
Generally, male adolescents engaged more in current alcohol use than female adolescents in this study, which concurs with some other studies $(2,7)$. This gender difference may be in some way attributed to socio-cultural norms that hinder girls from engaging in substance use (24). However, it seems Thai adolescent girls who drink, engage in binge drinking in the same way as boys do.

In concurrence with other studies $(9,10)$, this study found that current alcohol use was associated with other substance use (smoking and illicit drug use among boys and smoking among girls). The study found that current alcohol use increased with age (at least among boys), which seem to concur with a number of other studies $(4,5,7,12)$. Other studies found that other health risk behaviour [physical fighting, being bullied, sexual activity, having sustained an injury and lack of school attendance] $(3,6,9,11-12)$ were associated with alcohol consumption, while in this study only physical fighting in boys and girls, sexual activity and injury among boys were associated with current alcohol use. Un- 
like in other studies $(3,6,9,10-13)$, this study did not find any association between psychosocial distress (anxiety, depression, suicidal behaviour) and alcohol use in multivariable analysis. In this study, lack of protective factors such as parental or guardian connectedness was associated with alcohol use among girls, which is similar to findings in other studies $(9,12-13)$. This finding may suggest that girls would benefit from participating in programmes aimed at improving parent-child communication (25). Finally, girls with hunger or poverty were more likely to engage in current alcohol use. In a study among school-going adolescents in four African countries who reported hunger, they were at increased risk for at least two or more emotional or behavioural (including alcohol use) adverse outcomes (26). This needs further investigation.

This study had several limitations. Firstly, the GSHS only enrolls adolescents who are in school. School-going adolescents may not be representative of all adolescents in a country as the occurrence of alcohol use may differ between the two groups. Also, we did not assess regional and urbanrural differences in alcohol use. As the questionnaire was self-completed, it is possible that some study participants may have misreported either intentionally or inadvertently on any of the questions asked. Intentional misreporting was probably minimized by the fact that study participants completed the questionnaires anonymously. The questionnaire used in this study measured different concepts such as psychosocial distress variables with single items, which are quite limited in their use as quantitative indices. Another limitation was that a number of risk factors associated with alcohol use found in other studies such as adverse childhood events (14), family members with alcohol problems $(4,15)$, peers drinking alcohol (15), alcohol expectancies $(16,17)$, personality characteristics (16) and academic performance (4) were not assessed and should be assessed in future studies. Furthermore, this study was based on data collected in a cross-sectional survey. We cannot, therefore, ascribe causality to any of the associated factors in the study.

\section{CONCLUSION}

The prevalence of alcohol use among school-going adolescents in Thailand is similar to what is reported from previous studies. Efforts to prevent and control alcohol misuse may need to address a cluster of risk behaviours including cigarette smoking, and in boys illicit drug use, sexual activity, physical fighting and getting injuried. The results can be used as evidence that a constellation of behavioural factors exists with current alcohol use among Thai adolescents. The public health implication of interest in this study may be that it is reasonable to broaden the alcohol use health promotion message among adolescents to also include other problem behaviours such as illicit drug use, sexual activity, physical fighting and injury and encourage parental support. A Parent School project could support parents and/or guardians to become more understanding and caring of their children.

\section{ACKNOWLEDGEMENTS}

We are grateful to the World Health Organization (Geneva) for making the data available to us for analysis. We also thank the Ministries of Education and Health and the study participants for making the Thailand Global School Health Survey 2008 possible, and the country survey coordinator, Dr Pensri Kramomtong, Chief, Department of Health, Ministry of Public Health. The government of Thailand and the World Health Organization did not influence the analysis, nor did they have any influence on the decision to publish these findings.

\section{REFERENCES}

1. Nixon K, McClain JA. Adolescence as a critical window for developing an alcohol use disorder: current findings in neuroscience. Curr Opin Psychiatry 2010; 23: 227-32.

2. Assanangkornchai S, Sam-Angsri N, Rerngpongpan S, Lertnakorn A. Patterns of alcohol consumption in the Thai population: results of the National Household Survey of 2007. Alcohol Alcohol 2010; 45: 27885 .

3. Assanangkornchai S, Mukthong A, Intanont T. Prevalence and patterns of alcohol consumption and health-risk behaviors among high school students in Thailand. Alcohol Clin Exp Res 2009; 33: 2037-46.

4. Chaveepojnkamjorn W, Pichainarong N. Drinking behavior among female high school students in central Thailand. J Med Assoc Thai 2009; 92 (Suppl 7): S1-7.

5. Chaveepojnkamjorn W, Pichainarong N. Factors associated with alcohol consumption among male high school students in central Thailand. Southeast Asian J Trop Med Public Health 2010; 41: 735-42.

6. Chaveepojnkamjorn W, Pichainarong N. Current drinking and healthrisk behaviours among male high school students in central Thailand. BMC Public Health 2011; 11: 233.

7. Pichainarong N, Chaveepojnkamjorn W. Youth and alcoholic beverages: drinking patterns among high school students in central Thailand. Southeast Asian J Trop Med Public Health 2010; 41: 1467-74.

8. Assanangkornchai S, Pattanasattayawong U, Samangsri N, Mukthong A. Substance use among high-school students in Southern Thailand: trends over 3 years (2002-2004). Drug Alcohol Depend 2007; 86: 16774.

9. Siziya S, Rudatsikira E, Muula AS. Alcohol use among school-going adolescents in Harare, Zimbabwe: results from the 2003 Global Schoolbased Health Survey. Tanzan J Health Res 2009; 11: 11-6.

10. Saban A, Flisher AJ. The association between psychopathology and substance use in young people: a review of the literature. J Psychoactive Drugs 2010; 42: 37-47.

11. Sindelar HA, Barnett NP, Spirito A. Adolescent alcohol use and injury. A summary and critical review of the literature. Minerva Pediatr 2004; 56: 291-309.

12. Alwan H, Viswanathan B, Rousson V, Paccaud F, Bovet P. Association between substance use and psychosocial characteristics among adolescents of the Seychelles. BMC Pediatr 2011; 11: 85.

13. Peltzer K. Prevalence and correlates of substance use among school children in six African countries. Int J Psychol 2009; 44: 378-86.

14. Kabiru CW, Beguy D, Crichton J, Ezeh AC. Self-reported drunkenness among adolescents in four sub-Saharan African countries: associations with adverse childhood experiences. Child Adolesc Psychiatry Ment Health 2010; 4: 17.

15. Chaveepojnkamjorn W, Pichainarong N. Factors associated with alcohol consumption among upper secondary school students. Southeast Asian J Trop Med Public Health 2007; 38: 146-51.

16. Schulte MT, Ramo D, Brown SA. Gender differences in factors influencing alcohol use and drinking progression among adolescents. Clin Psychol Rev 2009; 29: 535-47.

17. Newman IM, Shell DF, Li T, Innadda S. Buddhism and adolescent alcohol use in Thailand. Subst Use Misuse 2006; 41: 1789-800. 
18. Ministry of Public Health Thailand. The Global School-based Student Health Survey (GSHS) in Thailand, 2008. Bangkok: Ministry of Public Health Thailand; 2008.

19. Centers for Disease Control (CDC). Global School-based student Health Survey: background [Online]. 2009; Available from: http://www. cdc.gov/gshs/background/

20. Prochaska JJ, Sallis JF, Long B. A physical activity screening measure for use with adolescents in primary care. Arch Pediatr Adolesc Med 2001; 155: 554-9.

21. Gomes Bda M, Alves JG, Nascimento LC. Alcohol consumption by public school students in Greater Metropolitan Recife, Pernambuco State, Brazil. Cad Saude Publica 2010; 26: 706-12.

22. National Institute of Alcohol abuse and alcoholism (NIAAA). NIAAA council approves definition of binge drinking. NIAAA newsletter 2004; 3: 3 .
23. Stolle M, Sack PM, Thomasius R. Binge drinking in childhood and adolescence: epidemiology, consequences, and interventions. Dtsch Arztebl Int 2009; 106: 323-8.

24. Reddy P, Resnicow K, Omardien R, Kambaran N. Prevalence and correlates of substance use among high school students in South Africa and the United States. Am J Public Health 2007; 97: 1859-64.

25. Spoth RL, Redmond C, Shin C. Randomized trial of brief family interventions for general populations: adolescent substance use outcomes 4 years following baseline. J Consult Clin Psychol 2001; 69: 627-42.

26. Swahn MH, Bossarte RM, Gaylor E, Musa Elimam D, Walingo MK. Hunger and risk for emotional and behavioral problems: a comparison between students in Botswana, Kenya, Uganda and Zambia. Intern Public Health J 2010; 2: 185-94.

\title{
The Diabetes Centre
}

1 Downer Avenue

Kingston 5, Jathatca, WI

(4hone: $(876) 97 \mathrm{~g}-2173$

Fax: $(876) 978-2510$

\section{SERVICES OFFERED BY THE CENTRE}

\author{
Medical/Surgical Consultations \\ Diet Counselling \\ Eye Clinic \\ Chiropody (Foot Care) \\ Hagmodialysis \\ Eye Laser Treatment \\ Pharmacy
}

\section{Routine Checks}

